Please quote as: Janson, A.; Söllner, M. \& Leimeister, J. M. (2016): The Appropriation of Collaborative Learning - Qualitative Insights from a Flipped Classroom. In: Hawaii International Conference on System Sciences (HICSS), Kauai, Hawaii, USA. 


\section{The Appropriation of Collaborative Learning - Qualitative Insights from a Flipped Classroom}

\author{
Andreas Janson \\ Information Systems, Kassel \\ University \\ andreas.janson@uni-kassel.de
}

\author{
Matthias Söllner \\ Information Systems, Kassel \\ University \\ soellner@uni-kassel.de \\ Institute of Information \\ Management, \\ University of St. Gallen \\ matthias.soellner@unisg.ch
}

\author{
Jan Marco Leimeister \\ Information Systems, Kassel \\ University \\ leimeister@uni-kassel.de \\ Institute of Information \\ Management, \\ University of St. Gallen \\ janmarco.leimeister@unisg.ch
}

\begin{abstract}
Collaborative learning is an important part of innovative learning scenarios such as flipped classrooms. However, little insights are available regarding the appropriation process of collaborative learning. Based on adaptive structuration theory, we derive insights on the appropriation process of collaborative learning by means of a qualitative approach. The results show that appropriation is characterized by initial appropriation and taskrelated discussions. Moreover, an analysis of the identified appropriation junctures indicates the crucial role of information technology in the learning process as well the impact of appropriation patterns on interaction. For one, the present paper theoretically contributes to the scientific discussion concerning collaborative learning appropriation and its evolving nature. Second, it also makes a practical contribution by deriving implications for collaborative learning in flipped classrooms.
\end{abstract}

\section{Introduction}

"The past decade has witnessed a dramatic increase in the development of technology-based teaching and learning" [1, p. 1]. This citation of Alavi and Leidner in their review regarding technologymediated learning (TML) from 2001 still holds true 14 years later. Teaching and learning changed tremendously in the past decade with the advent of concepts such as massive open online courses (MOOCs) and flipped classrooms. TML engages learning outcomes, facilitates cost advantages, and fosters the sharing of expertise in a global setting to provide learning opportunities at disadvantaged locations $[2,3]$. In addition, information technology
(IT) in the learning process allows for a new quality of self-directed and individual learning $[4,5]$, as well as collaborative learning (CL) [6]. The latter is especially prevalent in new teaching and learning scenarios such as MOOCs. CL with group discussions provides feedback and support in the learning process, which is otherwise not possible in such a large-scale teaching and learning concept.

Still, much further work is needed in CL concerning technology as an interaction medium as well as how learners employ different strategies in IT-supported CL. Following the suggestion of Gupta and Bostrom, the appropriation process in CL is one major driver of the learning process and learning outcomes [7]. Our goal is to enrich the body of knowledge regarding the appropriation of CL. Therefore, we draw on adaptive structuration theory (AST) and qualitative data to generate rich insights regarding CL appropriation. In specific, we apply a macro-level coding scheme from group support systems (GSS) research [8] to identify appropriations in group discussion forums embedded in a flipped classroom. The research questions (RQs) are:

(1) How is CL appropriated in a flipped classroom? and

(2) which patterns emerge regarding $C L$ appropriation?

By answering these RQs, we enrich on the one hand the body of knowledge regarding $\mathrm{CL}$ and its appropriation process as a theoretical contribution. On the other hand, we provide practitioners guidance on how to design CL that is faithfully appropriated in order to ensure learning outcomes. The remainder of this paper is structured as follows. After the provision of a theoretical background regarding IT-supported $\mathrm{CL}$ and AST, we introduce our research setting and the macro-level coding scheme in section three. Section four presents our findings, before section five 
discusses the CL appropriation patterns accordingly. In section six, we highlight possible limitations of our study and call for future research activities, before the paper closes with a brief conclusion.

\section{Theoretical Background}

\subsection{Collaborative Learning}

$\mathrm{CL}$ is a process concerning learners who interact, work, and learn together as a team in small groups of two or more, accomplishing a shared goal beneficial to all [9-11]. Thereby, students are not only responsible for their own learning outcome but rather for the outcome of the whole group [12]. CL thus enhances critical thinking [12], student satisfaction with the learning process, as well as learning outcomes. It creates a positive emotional learning climate through the construction and internalization of knowledge by means of the active and social interaction in a team of peers [6]. Peer learning as a concept of $\mathrm{CL}$ is based on theories of social constructivism and refers to learning with and from companions of an equal status, called peers [13]. Such a team comprises two major categories of peer influences that first serve as natural teachers and second contribute to task orientation, persistence, and motivation [14].

CL has been found to be more effective on the learning outcome of students than traditional instructional methods [9]. Mediated by IT, it also enables to overcome long geographical distances, therefore minimizing costs for education and training $[6,11]$. However, information systems research in CL lacks a profound understanding of the learning process [14]. To close this gap, we draw on the theoretical basis of AST in the next section.

\subsection{Adaptive Structuration Theory}

To examine the CL process and its appropriation, we draw on the theoretical basis of AST, which allows to investigate the relationship between technology and social structures, e.g., the use of group decision support systems in organizations [15]. AST, developed by DeSanctis and Poole [15] based on Gidden's structuration theory [16], is a metatheory [17] describing the social existence of a group beyond their information processing activities [18]. According to them, the social aspect of group work determines the adoption of technology supporting their own working processes, and therefore influences the information process and interaction features within the internal group work, and finally their output.

These thoughts are based on two premises [7]. The first one relates to the correlation of structures embedded in a specific context and is defined as rules, resources, and capabilities in a given context [15]. Applying this in CL, we consider the learning methods and structures that are, for example, reflected by the deployment of IT such as a learning management system (LMS). The second premise focuses on the user of an IT artifact, e.g., the interaction between the learner and the provided structures. In our setting, appropriation is defined as a group's decision on whether or not to use certain structures. A group might decide to directly use (reproduce) a collaborative learning structure, to relate or blend a collaborative learning structure with another structure, or to interpret the operation or meaning of a collaborative learning structure [15]. This appropriation process is in itself a complex phenomenon and includes cognitive processes and interactions relating to the learning methods, as well as support in the learning process (i.e., scaffolding) and other elements of the learning scenario influencing learning success [7]. The latter represents "the goal assessment or measures for determining the accomplishment of learning goals" [7, p. 713], and is the key outcome measure of CL.

AST posits that specific structures such as an LMS consist of a spirit which is reflected by the "general goals and attitudes the technology aims to promote" [19, p. 179], as well as structural features that implement the spirit promoted by the provided structures [20]. The spirit is formed by the learning goals and epistemological perspectives and guides design and implementation of the learning method that are appropriated in the learning/use process by the learners. Attitudes, namely the consensus of a group on how IT should be used, as well as faithfulness determine the appropriation process according to AST [20]. In this paper, we draw on the concept of faithfulness appropriation as a significant determinant for CL outcomes [21].

Faithfulness as a social aspect [15] regarding the use of technology can be observed as certain perceptions about the role and utility of the technology are created. Faithfulness with regards to the appropriation process is defined as the extent to which the provided structural potentials are used in a manner that is consistent to the underlying spirit of CL $[18,15,20]$. Referring to CL, a faithful appropriation occurs when the learning methods and structures are appropriated in consistence with the overall learning goals and epistemological perspective, which represent the underlying spirit, 
and in turn positively influence learning outcomes [7]. An example would be the use of a forum in an LMS to discuss learning materials. In contrast, an unfaithful or ironic appropriation occurs if learners do not fully comprehend a sophisticated LMS and need to shift their focus on understanding the technology itself. This consequently detracts from the overall learning process [7] and hence negatively influences learning outcomes such as learning success.

In the case of learning group members, we refer to the appropriation process of CL structures that deals with the perceptions of rules and norms [7]. CL supported by IT, e.g., by means of discussion forums, offers the possibility to interact with peers and therefore enables a more interactive way of knowledge acquisition and sharing. Nevertheless, if these structures are not well appropriated, they do not support learning success [11]. This might be the case if a discussion forum is not perceived as a support in the learning process or does not provide feedback. Hence, we consider in line with Gupta and Bostrom $[21,7]$ that the perceived richness of CL suggests its appropriation and ultimately leads to higher learning outcomes [11].

\section{Collaborative Learning Appropriation in Flipped Classrooms}

\subsection{Research Setting}

In our investigation of CL appropriation, we refer to the case of a flipped classroom. The approach of a flipped classroom, also known as ,inverted classroom" [22], changes the conventional way of lectures and self-regulated learning. Thus, the process of acquiring knowledge or learning contents takes place at home. Learners are required to teach themselves basic knowledge as homework, while they solve tasks that are usually supposed to be homework in class. This means that mastery activities are now an integral part of the schedule in class. Outside of class, learners have access to online videos and learning material to study the subject matter on their own. In class, learners concentrate on understanding, applying, and analyzing the subject matter they previously studied [23]. This is realized via group or individual problem-solving activities, group discussions, or other learner-centered activities that enhance critical thinking, problem-solving skills, or discussing [24, 25, 22].

Our analyzed lecture is held at a European university in the semestral course Introduction to Business and Information Systems Engineering, which is attended by 100 to 300 undergraduate students. In contrast to typical flipped classrooms, this lecture includes online collaboration activities in group discussion forums in addition to an online preparation with videos and quizzes in order to engage peer learning before discussing the peer learning activities during a presence phase in the lecture hall [26]. Since we want to focus on the ITsupported collaborative part of the flipped classroom, we concentrate our analysis on the online collaboration in group discussion forums. This part of the course is in our case embedded in an LMS, where we provided all learning materials as well as a Google Docs presentation document by means of which each group could visualize their ideas and solutions for the assignment.

The learners self-selected a group and could not see who else had chosen the specific group to avoid self-selection biases. In addition to the online discussions, the group members also met during the semester in tutorials on business process management conducted by student assistants. These tutorials were not further related to the solving of the group tasks in the discussion forums. Hence, we did not consider to audio- or videotape recordings of these sessions. The majority of learners were in their first year of university and had no prior experience with the LMS. This enabled us to account for LMS expertise in our sample. Prior to the first task, the learners were given information regarding the use of the LMS and its underlying philosophy, the purpose of the group discussions, as well as guidance on how to accomplish the task as a group. Throughout our study, learners were fully responsible for deciding whether, when, and how to use the LMS and Google Docs to finish the assignments. The first author was available during the semester to resolve difficulties with the LMS or Google Docs. Each group had the task to solve five assignments during the semester in the CL phase, and each assignment was related to one course topic. The assignments themselves were structured in a way that every group solved independent parts of the assignment.

\subsection{Data Collection and Participants}

The data collection took place in the described flipped classroom setting. The study was conducted with seven groups $(n=109)$ with a (theoretical) maximum number of 30 learners per group in the described course Introduction to Business and Information Systems Engineering in the winter term $2014 / 15$. On average, every group consisted of 20 learners (S.D.=8.22). Table 1 depicts the according demographics. 
Table 1. Demographics

\begin{tabular}{|l|l|}
\hline Description & Value \\
\hline Gender & \\
Female (n=56) & $51 \%$ \\
Male ( $\mathrm{n}=52)$ & $48 \%$ \\
No Answer ( $=1$ ) & $1 \%$ \\
\hline Age & \\
Mean (S.D. 2.68) & 24.1 Years \\
Median & 24.0 Years \\
Range & $20-33$ Years \\
\hline Major & \\
Business Administration $(\mathrm{n}=106)$ & $97 \%$ \\
Humanities (n=2) & $2 \%$ \\
Computer Sciences $(\mathrm{n}=1)$ & $1 \%$ \\
\hline
\end{tabular}

\subsection{Research Method}

Analyzing textual data is one of the most prevalent techniques in qualitative research [8]. Within our research context, textual data includes the group discussion in the LMS. Therefore, we collected data from the group discussion forums to analyze the qualitative data with regards to the appropriation process of CL. For this purpose, we exported all group discussions from the LMS to code and analyze the discussions accordingly. Coding in general refers to the process of breaking down data, conceptualizing it, and putting it back together in new ways [27]. Positivist coding approaches rely on the categorization of interactions, counting instances, and using statistical techniques for analyzing purposes. One example for a positivistic approach is the microlevel coding scheme by Poole and DeSanctis [28] to code structuration and appropriation movies. We in turn rely on a linguistic and interpretative approach for coding and analyzing the appropriation process, in specific the macro-level coding scheme of Chudoba [8]. In contrast to micro-level coding, such a scheme allows researchers to analyze larger samples to gain insights regarding appropriation and structuring activities. The scheme considers junctures in group work and may either be an actual change in what the group is doing or an attempt by a group member to change the group's activity [8].

Three important points have to be considered when coding the group discussions in our LMS. First, when coding group discussions, each juncture is coded exclusionary with one applicable type of juncture. Second, junctures are used to categorize an entire topic that may include more than one sentence and more than one participant in the group discussion, as long as the purpose of the exchange stays the same. Moving from one type of juncture to another might be linear, but in some cases, a group might move back and forth between different types of junctures. Third, the juncture identification is only the first step in analyzing data and should be proceeded by a detailed analysis of what happens at each juncture in order to create impressions of how groups use CL, thus capturing rich insights regarding the appropriation process.

For coding the junctures in our group discussion forums, we draw on a modified version of the coding scheme by Chudoba [8]. The original purpose of the scheme was to analyze verbal and electronic discussions of groups using GSS. Since we want to gather insights regarding the appropriation process of asynchronous electronic discussions, we slightly modified the original coding scheme and disregarded all junctures related to verbal discussion, as well as individual reflection in terms of reading or thinking. We hence exclusively categorize the electronic discussions in the group forums where learners solve their tasks and assignments. Table 2 depicts the coding scheme used in the further analysis.

Table 2. Junctures to Assess Appropriation Junctures to categorize electronic conversations

EC Electronic Conflict or Dissatisfaction

EF Electronic Faithful (time spent using the GSS faithfully)

EI Electronic Ironic (time spent using the GSS ironically)

EP Electronic Process (how the task should be accomplished)

EK Electronic Task (what the group is working on)

ES Electronic Social (social conversation w/o task relation)

ET Electronic Technology (technology feature discussions)

XF Exogenous Force

TP Transition Point

Electronic task (EK) is used to identify group discussions that are related to discuss the assignment itself. Electronic process (EP) relates to discussions engaged with the problem solution process the group should adopt. For example, when a group considers software development process models and one learner states "I think prototyping is the best solution because ...," this is coded EK, while "Why don't we take a vote on the best process model for our app development project?" is coded EP. Both codes are differentiated in line with research on GSS and CL $[8,21]$ in order to gain insights regarding the learning process.

Electronic faithful (EF) and electronic ironic (EI) are used as codes to indicate whether group members appropriated the group forum and its features according to its underlying spirit, i.e., the underlying learning goals and epistemological perspective. Considering our group discussion forum, we aim to achieve high cognitive learning goals related to analyzing, evaluating, and creating with a constructivist perspective [29], treating faithfulness as an objective measure [18]. Discussions are coded 
EF if the group brainstormed ideas. In contrast, discussions are coded EI in case the learners did not recognize the provided features. This might even result in insufficient learning outcomes, e.g., if not all group members were able to contribute or add value to the achieved assignment solution.

Electronic social (ES) is applied if discussions were related to private matters rather than to achieving the learning goals. Electronic conflict (EC) is used in the context of a negative judgement by one or more learners regarding the group, respectively a learner enunciated dissatisfaction with the provided technology structures. Discussions about the technology itself are coded electronic technology (ET) and relate to the use of features provided within our LMS or Google Docs. Exogenous forces (XF) which might relate to hardware problems are also considered. Finally, transition points (TP) between two periods in editing the assignment are coded as well, e.g., if a group had finally chosen a process model for software development and then actually applied it to a specific case.

\section{Results}

\subsection{Coding of Group Discussions}

All group discussions were coded by an independent researcher familiar with AST. The coder was introduced to the coding scheme and ambiguities were discussed with the first author, who independently coded a sample of five randomly chosen group discussions to determine inter-coder reliability. The inter-coder agreement on identifying junctures was 0.914. On this basis, one critical juncture type was identified (XF) that was coded differently. We therefore adjusted the XF juncture coding based on a mutual agreement, where applicable. Table 3 depicts the summary of a coded group discussion to illustrate the coding procedure.

Table 3. Exemplary Coded Group Discussion Group 3 Assignment 1

EP Participant 1 greets the group and suggests that it would be best to get started on the discussion.

EF Participants 1-5 subsequently brainstorm ideas and solution information to solve the assignment.

EP/ Participants 1, 6, and 7 discuss and summarize the

EF brainstormed information regarding the assignment.

ET Participant 5 has technical issues with Google Docs.

EI Subsequently, participant 5 uploads the group assignment as PDF instead of using Google Docs.

EF Participant 8 adds final comments to the assignment.
A review of this coded group discussion shows a typical sequence in the group discussions starting with process-related discussions on how to actually solve the assignment. After an initial suggestion, the group brainstormed ideas and information related to the assignment solution. We coded this large part of the discussion as EF. Afterwards, the group moved on to process-related questions. However, the discussion moved back and forth concerning how to accomplish the task as well as new ideas. Hence, we coded this part of the discussion as EP/EF. Near the end of the group discussion, participant 5 had technical issues with the presentation tool embedded in Google Docs and consequently uploaded a PDF version of a local PowerPoint file. We coded this juncture as ET. Subsequently, an ironic appropriation occurred since this participant uploaded a noneditable PDF file that inhibits all CL opportunities. One participant still added final comments to the group assignment, which was added on the Google Docs presentation.

\subsection{Appropriation Patterns}

As described above, we coded every group discussion. In total, 236 junctures were coded, whereas discussions that moved back and forth between two junctures account for the multiple coding of junctures. Each juncture of the seven groups related to the five assignments is shown in Table 4.

An analysis of the depicted code patterns indicates that the learners participated in some or all of the following activities while solving the group assignments. The first pattern involves process discussions in line with a faithful use of the LMS for brainstorming ideas or collecting material related to the task $(\mathrm{EP} / \mathrm{EF})$. The process discussions helped the groups to get initial orientation in the learning process, and the LMS provided the learners with a CL space to achieve the assignment solution. The second code pattern that emerged across the majority of groups is the sequential progression from taskrelated discussions to the faithful use of the LMS (EK-EF). These patterns often appeared at the middle and/or the end of a group discussion, indicating that groups worked on solving a task but task-related discussions did not emerge without a certain progress in the learning process. The third pattern that emerged constitutes discussions related to the task and the process for solving the task (EK-EP). Similar to the EK-EF pattern, this pattern often occurred at the end of the group discussions. This specific pattern also occurred in accordance with a faithful use of the LMS afterwards (EK-EP-EF). 
Table 4. Summary of Junctures

\begin{tabular}{|c|c|c|c|c|c|}
\hline Group & Assignment 1 & Assignment 2 & Assignment 3 & Assignment 4 & Assignment 5 \\
\hline 1 & ET/EP-TP-EF-EP/EF & EF-EK-EF-EP-ET-EK-EF & EF-EK & $\mathrm{EF}$ & $\mathrm{EF}$ \\
\hline 2 & EF/EP-EK-EF/EP-TP-EP & $\begin{array}{l}\text { EF/EK-EP-EF/EK-EP- } \\
\text { EF-TP-FK-EF/EP }\end{array}$ & EP-EF-TP-EF/EP & EP/EF-EC-EF & $\mathrm{EF} / \mathrm{EP}$ \\
\hline 3 & EP-EF-EP/EF-ET-EI-EF & $\mathrm{EF} / \mathrm{EP}$ & $\mathrm{EF}$ & EF-EK-EF/EP & EP-EF-TP-EP/EK-EF \\
\hline 4 & EF-ET/EP/EF & $\mathrm{EF}$ & $\mathrm{EF}$ & EK-EF-EK-EP & $\mathrm{EF}$ \\
\hline 5 & $\begin{array}{l}\text { EP-ET-EF-EP/EK-EF- } \\
\text { EP/EK/EF-EC-EF-EK-EP- } \\
\text { EF }\end{array}$ & $\mathrm{EF} / \mathrm{EK}$ & EF-ET-EF & $\mathrm{EF}$ & EP-EF \\
\hline 6 & EF-EP/EK-ES-EF & EP/EF-EK-EP & EF-EI-EF & EF/EP-EI & EF-EP-EF \\
\hline 7 & EK/EF/EP-EP-EF & $\begin{array}{l}\text { EP/ET-TP-EF-EP/EC-EF- } \\
\text { EP-EK-EF }\end{array}$ & $\mathrm{EF} / \mathrm{EK}$ & EF-EP-EF & EF-EP/EF \\
\hline \multicolumn{6}{|l|}{ Legend: } \\
\hline $\mathrm{EC}$ & \multicolumn{2}{|c|}{ Electronic Conflict/Dissatisfaction } & Electronic Task & ET & Electronic Technology \\
\hline $\mathrm{EF}$ & \multicolumn{2}{|l|}{ Electronic Faithful } & Electronic Process & TP & Transition Point \\
\hline EI & \multicolumn{2}{|l|}{ Electronic Ironic } & Electronic Social & $\mathrm{XF}$ & Exogenous Force \\
\hline I & \multicolumn{3}{|c|}{ Discussion moved back and forth between these activities within the same time period } & - & juential events \\
\hline
\end{tabular}

Both coding patterns (EK-EF \& EK-EP) that were initially related to discussions on the group work itself but often appeared at the end of the discussions might be explained by asynchronous discussions. While some learners directly joined the discussion when we uploaded the task assignments, some learners joined just a day before the deadline.

After identifying the junctures and code patterns, we now analyze in accordance with Chudoba [8] how the groups proceeded when a juncture occurred during their $\mathrm{CL}$ process. In order to derive CL appropriation patterns, we reviewed the coded qualitative data of the electronic discussions in an iterative process. Four distinct patterns in appropriation emerged during the review: Conflicts with Technology, Domineering Group Members, Inanimate Appropriation, Determined Discussions. Details regarding the patterns are shown in Table 5.

Table 5. Collaborative Learning Appropriation Patterns

\begin{tabular}{|l|l|}
\hline $\begin{array}{l}\text { Patterns \& } \\
\text { Representative } \\
\text { Groups }\end{array}$ & \multicolumn{1}{c|}{ Group Characteristics } \\
\hline $\begin{array}{l}\text { Conflicts with } \\
\text { Technology } \\
\text { Groups 5, 7 }\end{array}$ & Technology and its features inhibit CL. \\
\hline $\begin{array}{l}\text { Domineering } \\
\text { Group Member } \\
\text { Group 7 }\end{array}$ & $\begin{array}{l}\text { Domineering group members solve } \\
\text { assignment on their own and inhibit CL. }\end{array}$ \\
\hline $\begin{array}{l}\text { Inanimate } \\
\text { Appropriation } \\
\text { Groups 1, 4,6 }\end{array}$ & $\begin{array}{l}\text { Limited interaction in forums between } \\
\text { group members result in an inanimate } \\
\text { appropriation of CL. }\end{array}$ \\
\hline $\begin{array}{l}\text { Determined } \\
\text { Discussions } \\
\text { Groups 1,2, 5 }\end{array}$ & $\begin{array}{l}\text { Junctures in discussions faded over time } \\
\text { and more determined discussions to solve } \\
\text { the collaborative task took place. }\end{array}$ \\
\hline
\end{tabular}

Conflicts with Technology refers to a pattern when appropriation of the provided collaborative structures is inhibited because the technology does not support the desired collaborative processes. For example, in group 7, participant 1 (assignment 2) of the group remarks (EP/EC juncture):

I'm generally assuming that the future tasks will include subtasks, so I wanted to ask you all if it would make sense to open a Facebook group in order to distribute the tasks more efficiently and, above all, to know who else is in our group to get more clarity. At the moment, I think it's still relatively opaque when it comes to group work. If you missed 5 postings, one must first read them and before you've had the chance to respond, the next message has already been sent.

This posting relates to problems with the use process of the Moodle LMS and its implementation in the personal learning process. As in this example, Moodle is a learning content management system for the learner, and not really related to and thus unsupportive of CL. Hence, alternative collaboration tools are suggested, in this case a Facebook group. As such, these groups are more responsive, offering device independency and a more responsive way to discuss things with each other. Nevertheless, in a process discussion to solve the future tasks, the group decided to stick with Moodle, since not every student is registered on Facebook. Participant 2 of group 7 states (assignment 2):

Regarding Facebook: there would be the same problem as now: if much has been written, one has only to read a lot:-) secondly perhaps not everyone has Facebook. Personally, I would continue to use the platform Moodle.

In addition, as the second tool provided, Google Docs presentation was responsible for the majority of ET junctures. These issues were related to the use of Google Docs on mobile devices and its offline use. However, the groups usually resolved these issues by using the features of the Moodle LMS, as well as by 
seeking advice from other group members who would recommend how to deal with the technical problem and suggest a process that eventually worked for the group. This pattern occurred for example within EP discussions.

Domineering Group Member refers to learning groups where one learner is able to control and affect a significant portion of the group work [8]. We discovered such a pattern in Group 7 at an EC juncture when participant 5 of the group states:

Hello, I just wanted to ask if we could agree on the point that everyone in the group has a chance to acquire the needed knowledge for solving the task. Otherwise, on the long run usually one person does the whole assignment and no one gets the chance to contribute.

Considering this conflict, participant 5 suggests to limit the time for editing the assignment. In consequence, the "domineering" learning group participant 4 ironically suggests to limit the contributions of each learning group member in order to avoid such contribution conflicts with one domineering group member. Member 5 also posted:

Hey, if I remember correctly, you are the one who posted the solution to the first assignment just two days after the assignment was online. Without judging this in a negative way...! I do not see in any of the postings some kind of bestpractice solution or a solution that can be seen as "correct". Hence, everyone has the chance to contribute with their solution, improvements or changes.

As such, there was no "best-practice" solution to the tasks, since these assignments addressed high cognitive learning outcomes, and are thus of a complex nature. However, group members perceived this very differently, especially in our case when one or two group members domineered the group and worked on a quick solution. This solution was still found to be correct by the other group members and was consequently not challenged. This behavior occurred in several groups over the winter term.

The described points also correspond to Inanimate Appropriation of the provided collaborative structures, which refers to a limited interaction of the peers in their groups and hence an appropriation that is not related to the overall learning goals and underlying epistemological perspective of our CL spaces. We discovered this limited interaction when analyzing typical juncture patterns such as EP-EF or EK-EF. There was some initial motivation to solve the task, but the LMS use was rather ineffective since the group members did not recognize the opportunities for CL. For example, group 6 (assignment 5) exhibited this pattern when different group members simply posted a bunch of information that was somehow related to the task (execution and discussion of a cost-utility analysis for an information system), but each posting was not related to any of the other postings. Considering the nature of this task as something the group could work on together and discuss results as well as the nature of such an analysis, e.g., its sensitivity to subjective judgements, the group decided to not discuss any of the postings. This also indicates that there was no group leader who could have effectively guided the process of solving the task, thus resulting in an inanimate appropriation of the LMS.

The last pattern that occurred is called Determined Discussion, referring to group discussions that are characterized by an absence of extensive group discussions and more determined discussions to finish the assignment. This appropriation behavior of the groups is also indicated when considering the amount of junctures over time. In consequence, appropriation changed over time resulting in an appropriation process that is determined by extensive discussions regarding nontask related aspects such as group conflicts or technical issues. Over time, this behavior fades and more determined discussions with the aim to solve the solution took place. Group learners used our Moodle LMS in line with Google Docs to post solutions to the assignments in a more efficient way, resulting in less junctures.

\section{Discussion and Implications}

In our study, we investigated the CL appropriation process by means of a qualitative analysis. For this purpose, we drew on GSS research and AST as a meta-theory to study the learning process by means of a coding scheme for the identification of appropriation junctures. We evaluated the appropriation process of CL in a study embedded in a highly IT-supported learning scenario, thus suitable to investigate TML appropriation [26]. In specific, we gain insights on CL in a flipped classroom. In our case, CL is an integral part of a learning activity before learners actually discuss and exercise in the lecture hall. Below, we will discuss the results regarding our two underlying RQs.

Considering our first RQ regarding $\mathrm{CL}$ appropriation, our results show that the initial appropriation process of CL is an important step for learning groups and determines the efficiency of the group work afterwards. Considering the summary of the junctures in all groups, we can state that the amount of junctures decreases in most groups over 
time. In addition, conflicts related to the group or technical problems with the CL tools, i.e., a Moodle LMS and Google Docs presentations, occurred at the beginning of the winter term. We yet observed that groups self-regulated accordingly and helped each other to resolve conflicts or technology problems without any intervention of a teacher or researcher. Hence, the application of CL in a flipped classroom might be a suitable approach for practitioners to enrich self-regulated learning phases by actively considering peers in the learning process. Although appropriation and the faithful use differed at the beginning of the winter term, group processes adjusted quickly and engaged CL. By providing guidelines for the CL use and its purpose, as well as frequently asked questions regarding technology use, we still ensured a basic level of appropriation. In this context, scaffolds such as scripting [30] known from educational research also serve as a practical design implication initially supporting the learner in their individual and group learning process [7, 4], thus sustaining a faithful appropriation by preventing learners from being overwhelmed. This allows the learning group to focus on the learning itself by means of an initial support in the learning process [32]. Otherwise, appropriation may be ironic due to the complex nature of the LMS [31].

For one, with respect to the discussion of the second RQ and the emerged appropriation patterns, our results indicate that there are basic patterns that emerged after coding the junctures in CL group discussions. The first one $(\mathrm{EP} / \mathrm{EF})$ relates to process discussions in line with faithful tool use. This pattern indicates the potentials of CL with peers in a flipped classroom, since they provided each other orientation in the learning process and consequently facilitated CL. Initially provided scripts that facilitate such a behavior might be suitable for practitioners. The two other basic juncture patterns (EK-EF and EK-EP) often occurred towards the middle or the end of a group task. This was a surprising result, since we expected task-related discussions at the beginning of a group discussion in order to achieve an initial understanding between all group members. Practice could address this by building shared understanding [33]. In flipped classrooms, practical implications would be the participatory walkthrough of an assignment during the lecture or a smaller group size. Since we had an average 20 learners per group in our sample, smaller groups might reach the point of a shared understanding earlier [34].

Second, we reviewed the junctures and identified four distinct patterns. We identified certain groups that exhibited conflicts with technology. In these groups, technology inhibits group activities.
Interestingly, several learners suggested own solutions to these problems, such as more responsive Facebook groups that are also available via mobile. This indicates a missing fit between our provided technology and the collaborative tasks. Hence, designers should validate the task-technology fit regarding their CL tools to ensure a positive impact by IT support in the learning process [35]. The other three identified patterns relate to interaction processes. Considering domineering group members, interaction processes are limited and should be addressed by interventions of the lecturer, leveraging the potentials of the whole group. Considering the pattern inanimate appropriation, we witnessed that sometimes interaction between the learners was limited and just a minimum level of interaction necessary to solve the task was established. However, research suggests the important role of interaction to ensure learning outcomes [36]. Designers of CL should acknowledge this particular impact by leveraging perceptions regarding CL to support the appropriation process. Possible starting points can be found in the work of Gupta and Bostrom [7] or in the domain of peer learning [13], e.g., more structured learning activities in peer groups and the facilitation of group interactions. This also relates to the already mentioned problem of a shared understanding regarding the assignments. The last pattern, determined discussion, refers to the influence of the appropriation process and its evolving nature over time. As suggested by research in TML [7] or GSS, appropriation changes over time and the impact of a putative missing fit between task and technology fades [37]. In addition, group cohesion might establish over the semester, leading to a higher efficiency. Hence, one practical implications is the fostering of group cohesion in the beginning.

\section{Limitations and Future Research}

Our analysis of the appropriation process for CL is not without limitations. The internal validity of our study could be threatened by the coding procedure that analyzed only the electronic written communication in our Moodle LMS. First, we provided the learners with Google Docs as a second tool for the CL process. Therefore, it would be desirable to gain further insights regarding the collaborative use process of such a presentation tool for collaboration purposes. However, in order to prevent adoption issues, we decided to let learners use Google Docs on an anonymous basis. Thus, we are not able to track the use processes of the Google Docs presentations, where learners created their 
solutions. Second, we are not aware of how the learners participated in the asynchronous discussions regarding the assignments in the CL space. We could not address both issues, since our study is embedded in an on-going research project [26]. Future research could address this issue-related internal validity by means of a more profoundly controlled experimental procedure and/or methods such as diary studies in order to gain detailed insights on the individual appropriation process, thus offering multi-level insights based on AST [38]. However, we could not evaluate the specific impact of CL on individual and group learning outcomes. We also assessed faithfulness from an objective perspective that could be enriched by subjective assessments [18].

External validity of the present study could be endangered because we specifically investigated how learners appropriated CL spaces in a flipped classroom setting. This limits the generalizability of our study, since the research setting has some distinct features. In our case, learners in peer learning processes solved assignments prior to the actual lecture in presence. Hence, appropriation of $\mathrm{CL}$ should be investigated in other learning scenarios such as MOOCs. In this context, appropriation patterns might be different, since educational backgrounds of the according learners might not be as homogenous as in our university setting. In addition, MOOC learners might be distributed around the world, resulting in different cultural backgrounds of the learners. In consequence, research suggests to evaluate how such individual differences relate to the learning process in CL [7, 14]. Nonetheless, we offer first insights on how learners appropriate $\mathrm{CL}$ in an emergent learning scenario.

\section{Conclusion}

Appropriation in $\mathrm{CL}$ is crucial considering its application in a flipped classroom. To evaluate how appropriation influences CL, we drew on GSS research and AST to answer our RQs. For this purpose, we used a macro-level scheme for coding collaborative activities and collected according qualitative data. This data collection took part in a flipped classroom lecture with an LMS as an essential part of the learning scenario. The LMS hosts group discussion forums for CL. We coded all group discussions and analyzed them regarding the CL appropriation process. The according results indicate basic appropriation patterns related to initial appropriation and task-related discussions. Furthermore, we identified four patterns that are first related to technological issues and missing task- technology fit, as well as three patterns that considered interaction issues in the learning process that should be considered when designing CL for flipped classrooms. Overall, the application of a macro-level coding scheme for analyzing the appropriation process of $\mathrm{CL}$ is a promising way to gain insights by showing how and why CL appropriation changes over time [21]. This offers starting points for the design of CL environments that leverage learning outcomes among peers. This is especially prevalent since digitization is a major driver in learning scenarios and collaboration is one of the most promising approaches to ensure the success of IT-supported learning scenarios.

\section{Acknowledgements}

The research presented in this paper was partially funded by the German Federal Ministry of Education and Research in course of the project kuLtig (www.projekt-kuLtig.de), FKZ 01BEX05A13.

\section{References}

[1] Alavi, M. and D.E. Leidner, "Research Commentary: Technology-Mediated Learning--A Call for Greater Depth and Breadth of Research", Information Systems Research, 12(1), 2001, pp. 1-10.

[2] Webster, J. and P. Hackley, "Teaching Effectiveness in Technology-Mediated Distance Learning", The Academy of Management Journal, 40(6), 1997, pp. 1282-1309.

[3] López-Pérez, M.V., M.C. Pérez-López, and L. Rodríguez-Ariza, "Blended learning in higher education: Students' perceptions and their relation to outcomes", Computers \& Education, 56(3), 2011, pp. 818-826.

[4] Delen, E., J. Liew, and V. Willson, "Effects of interactivity and instructional scaffolding on learning: Selfregulation in online video-based environments", Computers \& Education, 78, 2014, pp. 312-320.

[5] Rubin, B., R. Fernandes, M.D. Avgerinou, and J. Moore, "The effect of learning management systems on student and faculty outcomes", The Internet and Higher Education, 13(1-2), 2010, pp. 82-83.

[6] Alavi, M., B.C. Wheeler, and J.S. Valacich, "Using IT to Reengineer Business Education: An Exploratory Investigation of Collaborative Telelearning", MIS Quarterly, 19(3), 1995, pp. 293-312.

[7] Gupta, S. and R. Bostrom, "Technology-Mediated Learning: A Comprehensive Theoretical Model", Journal of the Association for Information Systems, 10(9), 2009, pp. 686-714.

[8] Chudoba, K.M., "Appropriations and patterns in the use of group support systems", ACM SIGMIS Database, 30(34), 1999, pp. 131-148. 
[9] Alavi, M., "Computer-Mediated Collaborative Learning: An Empirical Evaluation", MIS Quarterly, 18(2), 1994, pp. 159-174.

[10] Dillenbourg, P., "What do you mean by collaborative learning: Collaborative learning: Cognitive and computational approaches", Elsevier, 1999, pp. 1-19.

[11] So, H.-J. and T.A. Brush, "Student Perceptions of Collaborative Learning, Social Presence and Satisfaction in a Blended Learning Environment: Relationships and Critical Factors", Computers \& Education, 51(1), 2008, pp. 318-336.

[12] Gokhale, A.A., "Collaborative Learning Enhances Critical Thinking", Journal of Technology Education, 7(1), 1995, pp. 22-30.

[13] Topping, K.J., "Trends in peer learning", Educational Psychology, 25(6), 2005, pp. 631-645.

[14] Gupta, S., R.P. Bostrom, and M. Huber, "End-user Training Methods: What We Know, Need to Know", SIGMIS Database, 41(4), 2010, pp. 9-39.

[15] DeSanctis, G. and M.S. Poole, "Capturing the complexity in advanced technology use: Adaptive structuration theory", Organization Science, 5(2), 1994, pp. 121-147.

[16] Giddens, A., The constitution of society: introduction of the theory of structuration, Univ of California Press, 1984.

[17] Bostrom, R.P., S. Gupta, and D. Thomas, "A MetaTheory for Understanding Information Systems Within Sociotechnical Systems", Journal of Management Information Systems, 26(1), 2009, pp. 17-48.

[18] Chin, W.W., A. Gopal, and Salisbury, W. David, "Advancing the Theory of Adaptive Structuration: The Development of a Scale to Measure Faithfulness of Appropriation", Information Systems Research, 8(4), 1997, p. 342.

[19] Poole, M. and G. DeSanctis, "Understanding the use of Group Decision Support Systems: The Theory of Adaptive Structuration", in Organizations and communication theory, J. Fulk and C.W. Steinfield, Editors. 1990. Sage Publications: Newbury Park, Calif.

[20] Gopal, A., R.P. Bostrom, and W.W. Chin, "Applying Adaptive Structuration Theory to Investigate the Process of Group Support Systems Use", Journal of Management Information Systems, 9(3), 1992, pp. 45-69.

[21] Gupta, S. and R. Bostrom, "An Investigation of the Appropriation of Technology-Mediated Training Methods Incorporating Enactive and Collaborative Learning", Information Systems Research, 24(2), 2013, pp. 454-469.

[22] Strayer, J.F., "How learning in an inverted classroom influences cooperation, innovation and task orientation", Learning Environments Research, 15(2), 2012, pp. 171193.

[23] Keengwe, J., G. Onchwari, and J.N. Oigara, Promoting Active Learning Through the Flipped Classroom Model, IGI Global, 2014.
[24] Garrison, D.R. and H. Kanuka, "Blended learning: Uncovering its transformative potential in higher education", The Internet and Higher Education, 7(2), 2004, pp. 95-105.

[25] So, H.-J. and T.A. Brush, "Student perceptions of collaborative learning, social presence and satisfaction in a blended learning environment: Relationships and critical factors", Computers \& Education, 51(1), 2008, pp. 318336.

[26] Oeste, S., K. Lehmann, A. Janson, and J.M. Leimeister, "Flipping the IS Classroom - Theory-Driven Design for Large-Scale Lectures", ICIS 2014 Proceedings, 2014.

[27] Strauss, A. and J.M. Corbin, Basics of qualitative research: Grounded theory procedures and techniques, Sage, 1990.

[28] Poole, M.S. and G. DeSanctis, "Microlevel Structuration in Computer-Supported Group Decision Making", Human Communication Research, 19(1), 1992, pp. 5-49.

[29] Bloom, B.S., Taxonomy of educational objectives, David McKay New York, 1956.

[30] Suthers, D.D., "Technology affordances for intersubjective meaning making: A research agenda for CSCL", International Journal of Computer-Supported Collaborative Learning, 1(3), 2006, pp. 315-337.

[31] Tennant, V., A. Mills, and W. Chin, "A Generalized Darwinism Perspective on Changes in Individuals' Use of Information Systems", ICIS 2014 Proceedings, 2014.

[32] Janson, A. and M. Thiel de Gafenco, "Engaging the Appropriation of Technology-mediated Learning Services A Theory-driven Design Approach", ECIS 2015

Proceedings, 2015.

[33] Bittner, E.A.C. and J.M. Leimeister, "Creating Shared Understanding in Heterogeneous Work Groups: Why It Matters and How to Achieve It", Journal of Management Information Systems, 31(1), 2014, pp. 111-144.

[34] Qiu, M., J. Hewitt, and C. Brett, "Online class size, note reading, note writing and collaborative discourse", International Journal of Computer-Supported Collaborative Learning, 7(3), 2012, pp. 423-442.

[35] McGill, T.J. and J.E. Klobas, "A task-technology fit view of learning management system impact", Computers \& Education, 52(2), 2009, pp. 496-508.

[36] Bitzer, P. and A. Janson, "Towards a Holistic Understanding of Technology-Mediated Learning Services - a State-of-the-Art Analysis", ECIS 2014 Proceedings, 2014.

[37] Fuller, R.M. and A.R. Dennis, "Does Fit Matter? The Impact of Task-Technology Fit and Appropriation on Team Performance in Repeated Tasks", Information Systems Research, 20(1), 2009, pp. 2-17.

[38] Bélanger, F., M. Cefaratti, T. Carte, and S. Markham, "Multilevel Research in Information Systems: Concepts, Strategies, Problems, and Pitfalls", Journal of the Association for Information Systems, 15(9), 2014. 